TITLE:

\title{
MARINE POLLUTION BIOASSAY BY SEA URCHIN EGGS, AN ATTEMPT TO ENHANCE ACCURACY
}

AUTHOR(S):

Kobayashi, Naomasa

CITATION:

Kobayashi, Naomasa. MARINE POLLUTION BIOASSAY BY SEA URCHIN EGGS, AN ATTEMPT TO ENHANCE ACCURACY. PUBLICATIONS OF THE SETO MARINE BIOLOGICAL

LABORATORY 1974, 21(5-6): 377-391

ISSUE DATE:

1974-12-23

URL:

http://hdl.handle.net/2433/175874

RIGHT: 


\title{
MARINE POLLUTION BIOASSAY BY SEA URCHIN EGGS, AN ATTEMPT TO ENHANCE ACCURACY ${ }^{1}$
}

\author{
NaOMASA KOBAYASHI \\ Biological Laboratory, Doshisha University, Kyoto
}

\section{Introduction}

The author proposed in 1971 the use of sea urchin eggs and embryos as indicatory materials in marine pollution bioassay and applied this to the survey of the sea water pollution in the Inland Sea of Japan (1972). That time, it was attempted to grade, though quite arbitrary, the sea pollution on the results of bioassay. Then the degree of pollution was checked by this grading in some later surveys. However, it has become clear that rather significantly different states of the water in COD, colour, or turbidity are met within the grade I, the water least polluted. Evidently, this seems to show the necessity of subdividing the grade I, and probably this will be done if the accuracy of bioassay can be enhanced. Thus, the change in the sensitivity of aging of unfertilized sea urchin eggs to some kinds of pollutants was examined in the following experiments.

\section{Material and Methods}

Eggs of Hemicentrotus pulcherrimus (A. Agassiz) (January to March) and Anthocidaris crassispina (A. Agassiz) (May to September) were left intact for some hours in each test water before they were inseminated and their rates of fertilization, first cleavage, gastrulation and some anomalies in the development were checked. Eggs were obtained by the current $\mathrm{KCl}$-method, being washed several times with fresh sea water, and were used as soon as possible, within 1 hour at the latest. Sperms were obtained from testes within 1 hour after being taken out of the test. The sperm density for insemination was standardized at about 1 dry sperm : 1000 sea water in volume. When it was necessary, the preliminary check of eggs was done to see if the fertilization membrane was elevated in 3 minutes after insemination in over $91 \%$ of eggs and if the well synchronized first cleavage occurred in over $91 \%$ of them in the control laboratory water.

Firstly the percent of eggs with elevated fertilization membrane to the total eggs observed was read. The first cleavage occurred in most cases about 90 minutes after the insemination at $17^{\circ} \mathrm{C}$ (warmed) or $45-60$ minutes after the insemination at $25^{\circ}$ -

1) Contributions from the Seto Marine Biological Laboratory, No. 593.

Publ. Seto Mar. Biol. Lab., XXI (5/6), 377-391, 1974.

(Article 24) 
$28^{\circ} \mathrm{C}$. Then, the rate and state of the first cleavage, namely proportions of undividing cells, normal two cells and multi-cells caused by polyspermy were checked at some adequate time. Two hundred eggs were fixed with $5 \%$ formaldehyde at a time for this examination. Lastly, the state of swimming embryos exclusive of those deposited on the bottom, namely proportions of permanent blastulae, normal gastrulae and abnormal exogastrulae were checked about 24 hours at $17^{\circ} \mathrm{C}$ or $12-15$ hours at $25^{\circ}-28^{\circ} \mathrm{C}$ after the insemination. Two hundred embryos were fixed at a time for this check. The check was repeated 3 times on different batches as to respective water samples.

\section{Results}

Aging of Sea Urchin Eggs and the Sensitivity of the Bioassay

If the unfertilized eggs are left for a long time after they are shed they will hardly be fertilized or never develop further and will die out (see Tyler and Tyler 1966). The sterile conditions may extend considerably the life-span of unfertilized eggs (Tyer et al 1938), and then the prolongation of the life-span of unfertilized eggs was achieved by Mertes and Berg (1962) by using antibiotics and sulfonamides.

When the aged eggs are inseminated, no fertilization will occur $36-52$ hours after shedding at $20-22^{\circ} \mathrm{C}$. In fertilized eggs, the formation of fertilization membrane may be retarded or missing, or the membrane may be formed closer to the egg; polyspermy increases with age; cleavage is seen in fewer eggs and slower and more irregular; cytolysis increases with age (see Harvey 1956).

These features seemingly occur more sensitively in aged eggs; in this respect they might be regarded as indicatory signs reflecting more sharply the degrees of marine pollution. The present experiments concerned (1) the process of egg aging as seen actually in fertilization and further development in Hemicentrotus pulcherrimus and Anthocidaris crassispina, (2) the marine pollution bioassay in Tanabe Bay, using aged eggs of these urchins, and (3) effects of some chemicals on fertilization and development of aged eggs.

1. The Fertilization and Further Development of Aged Eggs.

Hemicentrotus pulcherrimus (breeding season in January to March):

The running sea water of the Seto Marine Biological Laboratory was used as the fresh unpolluted sea water. A part of the eggs obtained by the current $\mathrm{KC1}$-method were washed several times with the sea water, and inseminated as soon as possible ( 0 hour to insemination), while the other unfertilized eggs were left in the sea water for different hours before insemination. Thus the effects of aging upon the fertilization, cleavage and gastrulation were observed (Table 1 ).

Successful fertilization and regular development were maintained in 6 hours old eggs, but the rate of fertilization drops below $90 \%$ and that of the first cleavage below $80 \%$ in 12 hours old eggs. Gastrulation was significantly disturbed in over 18 hours old eggs. Drop of the rate of fertilization was especially remarkable in over 36 hours 
old eggs and the rate reduced to zero in 60 hours old eggs. A rather sharp increase of polyspermy occurred in 24 hours old eggs and the significant increase of exogastrula was observed in 18 and 36 hours old eggs. Fertilized 48 hours old eggs developed mostly in abnormal forms.

Anthocidaris crassispina (breeding season in May to September):

The effects of aging upon the fertilization, cleavage and gastrulation appeared more rapidly in this sea urchin than in Hemicentrotus; this may be caused by higher temperature of the sea water (Table 2).

Successful fertilization was maintained in 3 hours old eggs, but the rate of the first cleavage dropped significantly already in 3 hours old eggs. Both rates dropped rapidly over 6 hours eggs. The polyspermy increased once in 6-9 hours old eggs, but reduced again in more aged eggs. In 18 hours old eggs, the rates of both fertilization and first cleavage were about $10 \%$, but no gastrulation was observed. In 24 hours old eggs no fertilization was observed and all eggs were destroyed by cytolysis.

In general, the age limit of unfertilized eggs maintaining the potential of normal development and presumably provided with sharpened sensitivity in the fresh sea water (control) was 6 hours in Hemicentrotus and 3 hours in Anthocidaris.

2. Application of Aged Eggs for the Marine Pollution Bioassay around Hatakejima Island in Tanabe Bay (Tables 3,4)

The marine pollution bioassay was carried out using aged eggs on the water samples collected from the four stations around Hatakejima Island as in previous studies (Kobayashi 1971).

The effects of aging ( $3,6,9$ hours old) upon the fertilization, the first cleavage, and gastrulation in the polluted sea water were learned by comparing the figures, concering these processes, obtained in respective test water samples with those observed as to 0 hour old eggs in the control water, the running sea water of the laboratory. And it was found that the effects become larger with the age and more pronounced with the degree of pollution. Actually the effects were seen most markedly in the water samples from the cove of Tsunashirazu where the water is polluted most heavily by sewage and waste products of fish rearing, etc.

The age limit for the maintenance of the normal developmental conditions, for instance the rate of fertilization and first cleavage over $91 \%$, was found again to be 6 hours in Hemicentrotus and 3 hours in Anthocidaris.

The same bioassay was applied for the water samples from other parts of Tanabe Bay than the area around Hatakejima Island and it was shown that the effects of pollution were reflected on aging of eggs more pronouncedly in the water samples from the harbours of Mori and Egawa (centers of lumbering) and some coves (places for fish rearing) of the Bay where the organic pollution is somewhat remarkable.

3. Effects of Some Chemicals on Fertilization and Further Development of Aged eggs.

The effects of various chemicals upon the indicatory developmental stages of 0 and 3 hours old eggs Anthocidaris crassispina were compared with each other and the 
results are given in Tables 5 and 6.

The concentration of chemicals is shown in tables by ppm of the main effective ion or component of respective chemicals. The chemicals are arranged in tables in the order from higher to lower degree of inhibitory effects. All the results as to the 0 hour old eggs seem to conform to those reported in the previous paper (1971), except the effect of ABS (alkyl benzen sulphonate).

\section{(1) Heavy metals}

The effects seemed to be more pronounced on 3 hours old eggs in solutions of mercuric chloride and cadmium chloride, but remain nearly the same in solution of other compounds. Generally speaking, the effects of heavy metals upon the aging of eggs are not so significantly larger.

(2) Other chemicals than heavy metals

The effects seemed to be more pronounced on 3 hours old eggs in solutions of ammonium chloride and phenol but remained nearly the same in other solutions. The effects of these chemicals upon the aging of eggs seem not to be so significantly pronounced, either. However, it is probable that some of them might be more effective on aging of eggs in coaction with other substances.

4. Inhibitory Effects of Sea Sludge upon the Fertilization and Further Development Checked Tentatively by Aged Sea Urchin Eggs.

Recently, the pollution of sea sediments has gradually been noted, but no appropriate method has yet been found to check this biologically. Although it is somewhat difficult to define exactly the process in which the sediments pollution affects the marine organisms, the pollutants caught in sediments may have some effects on pelagic forms when they are dispersed in the water by turbulence. In this respect, it was attempted to see the "relative" biological effects of polluted sea sludge by bioassay using the aging of sea urchin eggs.

A test experiments was made with the sludge collected from the waterway leading to a plating shop. At the same time, the drainage from that plating shop was checked as a control. The results are given in Table 7. The drainage from the shop was made saline by adding Jamarin, a commercial mixture for artificial sea water, to the salinity of the running sea water of the laboratory.

The drainage from the shop showed marked inhibitory effects on the fertilization and further development of aged eggs and the supernatant water of the mixture of black sludge from the waterway and the artificial sea water also showed similarly remarkable effects, but the sandy mud from the waterway was proved to be much less effective as seen in Table 7. This shows evidently the difference in biological harmfullness between the black sludge and sandy mud from the waterway from the shop.

\section{Considerations and Proposal of a New Manual for Bioassay}

It has been known that the treatment of eggs in developmental experiments needs more exactness in Mespilia than in Hemicentrotus and Anthocidaris and is rather diff- 
cult in Echinostrephus. This may be taken to show the higher sensitivity of Mespilia and Echinostrephus eggs, but the "nature" of such higher sensitivity have not yet been fully analized. The present experiments seem to show clearly that the effects of sea water pollution is more pronounced in aging of eggs, in other words the aged eggs a are more sensitive to the pollutants. However, the higher sensitivity of aged eggs of Hemicentrotus and Anthocidaris may probably be of some different "nature" from that of Mespilia and Echinostrephus eggs, as the treatment of aged eggs of the former sea urchins is much less difficult to produce the stable results.

Then, what is the reason why the effects of aging is prominent in polluted sea water? Whitaker (1937), Schechter (1937, 1941), Tyler et al. (1938), and Tyler and Dessel (1939) have demonstrated that the life span of unfertilized eggs of sea urchins and other animals can be prolonged by various agents such as weak alcohol, slight acidity, and low calcium content of the medium (see Tyler and Tyler 1966). As the maintenance of sterile conditions also extended considerably the life-span of eggs (Tyler et al., 1938), it was considered that the agents that are effective extenders of the life-span may operate by suppressing bacterial growth. In this respect, some recent experiments by Mertes and Berg (1962) have shown that various antibiotics and sulfonamides are effective in extending the life-span of sea urchin eggs.

The results of the present experiments show that heavy metals and other chemicals do not affect the aging of eggs so significantly, but the fertilization and further development of aged eggs were especially inhibited with the increase of the pollution by organic matter. This may suggest also the significance of the bacterial population.

Theoretically, it must be somewhat questionable to compare the pollution of different natures one another all at the same level and by only earlier developmental stages in a very short time. However, if any biological significance can be admited in such general comparison in a way, grading of the pollution degree must be inevitable. Thus, an improvement of the method of grading proposed in 1972 (the Ranking I) was attempted on the more exact results of experiments made with aged eggs of sea urchins. In aging, hours to insemination should be limited within the range in which the inseminated eggs can develop normally in the ordinary (unpolluted) sea water, though the abnormality will occur more sensitively in the polluted sea water; they are 6 hours in Hemicentrotus and 3 hours in Anthocidaris. However, these hours should be regulated properly according to the water temperature in different seasons. The new Ranking II is proposed in Table 8. Six grades, violent inhibition (5), strong (4), moderate (3), weak (2) and slight inhibition (1) and non-inhibitory (0) ordinary sea water were defined by checking respective normal and abnormal features, as noted in the Ranking I, appeared in the fertilization and further development of aged eggs of Hemicentrotus and Anthocidaris. The grade 5 of violent inhibition is set at $50 \%$ of fertilization and first cleavage as ID50 (inhibitory degree $50 \%$ ), somewhat comparable to LD50 (lethal dose $50 \%$ ). Other five grades, 4 to 0 , are set quite mathematically at 
every $10 \%$ of fertilization and first cleavage. After the first cleavage is done perfectly, the normal gastrulation is achieved at rather higher rates so that the grade 5 is set here at $75 \%$ and then other five grades are set at every $5 \%$. Polyspermic cleavage and formation of exogastrula occur rather infrequently and then the grades must be defined on a quite special standard. Such special standards are arbitrary but reflecting somewhat the actual figures seen in foregoing experiments. In general, the present Ranking II is more exact than the Ranking I. The Ranking I, treating only 0 hour old eggs, may be suitable to do with a large number of heavily polluted water samples. But when higher sensitivity is requested to check a smaller number of less polluted water samples, the Ranking II will be much better. The advantage of the Ranking II is especially great when the pollution is caused by organic matters. For instance, the water sample from inside the breakwaters at Egawa (Nov. 27, 1973) in Tanabe Bay was judged as grade 2 of the Ranking I but as grade 4 of the Ranking II. Therefore, for the bioassay of the marine pollution caused by heavy industries or chemical factories the Ranking I may be better in general than the Ranking II. The pollution of the Tanabe Bay is not yet so heavy and caused mainly by organic substances. Therefore, the Ranking II may be more suitable here than the Ranking I. Actually, the choice may depend upon the number of water samples. Now, it seems necessary to propose here a new manual of bioassay for the Ranking II. The new manual follows next procedures:

1. Unfertilized eggs are left in a glass bowl filled with respective test water for some hours before they are inseminated. Hours to insemination are 3 hours in summer in Anthocidaris (water temperature $26-28^{\circ} \mathrm{C}$ ), 9 hours in autumn in Pseudocentrotus depressus (A. Agassiz) (water temperature $13-16^{\circ} \mathrm{C}$ ) and 6 hours in winter in Hemicentrotus (water temperature $17-19^{\circ} \mathrm{C}$, warmed). The water temperature should be maintained stably in autumn and winter, when the temperature is variable.

2. It is desirable that a preliminary check is done to see if the fertilization membrane is elevated in 3 minutes after insemination on over $91 \%$ of eggs and the first cleavage occurrs synchronously over $91 \%$ of them.

3. When this bioassay is applied to compare the inhibitory effects of different sea sediment samples one another, the following procedures may be a way. The water is removed from the sample as far as possible and then the sample is homogenized by stirring. One part in volume of the sediments is mixed with 9 parts of artificial sea water, the mixture is shaken for 5 minutes then, kept still for 6 hours. The supernatant water is assayed as in the cases of polluted water.

4. In grading, take the lowest figure for normal features but the highest for abnormal ones, of course exceptional figures should be excluded. The grade of the pollution is represented by the highest grade throughout the whole indicatory features checked, as this will decide the survival rate (1972).

The author wishes to express his hearty thanks to the staff of the Seto Marine Biological Laboratory for a fund and facilities given to him in carrying out the re- 
searches at the laboratory, particularly to Professor Takasi Tokioka of the laboratory for advices and criticism and also for his kindness in reading the manuscript. My deep gratitude is also due to Emeritus Professor Masao Sugiyama of Nagoya University for important suggestions.

\section{Summary}

1. To improve the previous method (1971) especially in sensitivity, some experiments were made upon the aged sea urchin eggs.

2. The eggs were left in respective test water for some hours before they were inseminated. And then rates of fertilization, first cleavage, gastrulation and some anomalies in the test water were observed.

3. Various abnormalities, $i$. e. the retarded formation of the fertilization membrane or its lacking, polyspermy, irregular cleavage and development, etc., occurred more sensitively on aged eggs, and this seems to be available to bioassay of marine pollution.

4. Hours to insemination should be limited within the range in which the eggs follow the normal development in the ordinary (unpolluted) sea water, but the abnormalities occur more pronouncedly in the polluted water. They were 9 hours in Pseudocentrotus, 6 hours (warmed) in Hemicentrotus and 3 hours in Anthocidaris.

5. The effects of heavy metals and other chemicals upon the aging of the eggs are not so significant.

6. A new ranking of the sea water pollution (Ranking II) is proposed here tentatively as seen in Table 8. The Ranking II is more exact than the Ranking I; the former is available to see the effects of pollution more precisely, especially in the cases of organic pollution.

\section{REFERENCES}

Harvey, E. B. 1956. The American Arbacia and other sea urchins. Princeton, Princeton University Press, pp. 298

Kobayashi, N. 1971. Fertilized sea urchin eggs as an indicatory material for marine pollution bioassay, preliminary experiments. Publ. Seto Mar. Biol. Lab. 18: pp. 379-406.

Kobayashi, N., Nogami, H. and Doi, K. 1972. Marine pollution bioassay by using sea urchin eggs in the Inland Sea of Japan (Seto-Naikai). Publ. Seto Mar. Biol. Lab. 19: pp. 359-381.

Mertes, D. H., and W. E. Berg, 1962. Prolongation of the life span of unfertilized sea urchin eggs with antibiotics and sulfonamides. Acta Embryol. Morph. Exp. 5 : pp. 280-284.

Tyler, A., N. Ricci, and N. H., Horowitz, 1938. The respiration and fertilizable life of Arbacia eggs under sterile and non-sterile conditions. J. Exp. Zool. 79 : pp. $129-143$.

Tyler, A. and B. S. Tyler, 1966. The gametes; some procedures and properties. In Physiology of Echinodermata: pp. 639-682. New York, Interscience Publishers, pp. 822. 
Table 1. Fertilization and further development of aged eggs of Hemicentrotus pulcherrimus. Water temperature; $17^{\circ} \mathrm{C}$ (warmed).

\begin{tabular}{|c|c|c|c|c|c|c|c|}
\hline \multirow{2}{*}{$\begin{array}{l}\text { Hours to } \\
\text { insemination }\end{array}$} & \multirow{2}{*}{ 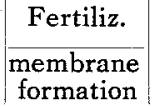 } & \multicolumn{3}{|c|}{ First cleavage ( $90 \mathrm{~min})}$. & \multicolumn{3}{|c|}{ Gastrulation ( $24 \mathrm{hrs}$ ) } \\
\hline & & 1 cell & $\begin{array}{c}2 \text { cell } \\
\text { (normal) }\end{array}$ & $\begin{array}{c}\text { multi-cell } \\
\text { (polyspermy) }\end{array}$ & $\underset{\text { permanent }}{\text { blastula }} \mid$ & $\begin{array}{c}\text { gastrula } \\
\text { (normal) }\end{array}$ & exogastrula \\
\hline 0 & $\begin{array}{l}99.9 \% \\
98.4 \\
98.7\end{array}$ & $\begin{array}{l}0.1 \% \\
1.6 \\
1.5\end{array}$ & $\begin{array}{l}99.8 \% \\
98.3 \\
98.3\end{array}$ & $\begin{array}{l}0.1 \% \\
0.1 \\
0.2\end{array}$ & \begin{tabular}{|l|}
$0.2 \%$ \\
0.1 \\
0.1
\end{tabular} & $\begin{array}{l}99.7 \% \\
99.7 \\
99.8\end{array}$ & $\begin{array}{l}0.1 \% \\
0.2 \\
0.1\end{array}$ \\
\hline 6 & $\begin{array}{l}99.9 \\
98.8 \\
99.6\end{array}$ & \begin{tabular}{l|}
1.1 \\
1.2 \\
1.1
\end{tabular} & $\begin{array}{l}98.9 \\
98.6 \\
98.7\end{array}$ & $\begin{array}{l}0.0 \\
0.2 \\
0.2\end{array}$ & \begin{tabular}{l|}
0.2 \\
0.1 \\
0.1
\end{tabular} & $\begin{array}{l}99.8 \\
99.8 \\
99.9\end{array}$ & $\begin{array}{l}0.0 \\
0.1 \\
0.0\end{array}$ \\
\hline 12 & $\begin{array}{l}89.8 \\
88.2 \\
89.2\end{array}$ & $\begin{array}{l}20.2 \\
21.5 \\
23.5\end{array}$ & $\begin{array}{l}79.5 \\
77.9 \\
76.1\end{array}$ & $\begin{array}{l}0.3 \\
0.6 \\
0.4\end{array}$ & $\begin{array}{l}0.4 \\
0.4 \\
0.5\end{array}$ & $\begin{array}{l}99.4 \\
99.3 \\
99.4\end{array}$ & $\begin{array}{l}0.2 \\
0.3 \\
0.1\end{array}$ \\
\hline 18 & $\begin{array}{l}80.3 \\
81.4 \\
80.9\end{array}$ & $\begin{array}{l}34.0 \\
27.5 \\
30.7\end{array}$ & $\begin{array}{l}65.2 \\
71.3 \\
68.3\end{array}$ & $\begin{array}{l}0.8 \\
1.2 \\
1.0\end{array}$ & $\begin{array}{l}2.3 \\
2.6 \\
4.8\end{array}$ & $\begin{array}{l}96.9 \\
95.5 \\
92.9\end{array}$ & $\begin{array}{l}0.8 \\
1.9 \\
2.3\end{array}$ \\
\hline 24 & $\begin{array}{l}75.2 \\
77.8 \\
79.8\end{array}$ & $\begin{array}{l}42.6 \\
42.5 \\
43.0\end{array}$ & $\begin{array}{l}56.0 \\
55.1 \\
52.8\end{array}$ & $\begin{array}{l}1.4 \\
2.4 \\
4.2\end{array}$ & $\begin{array}{l}14.3 \\
18.4 \\
16.5\end{array}$ & $\begin{array}{l}84.6 \\
79.8 \\
82.1\end{array}$ & $\begin{array}{l}1.1 \\
1.8 \\
1.4\end{array}$ \\
\hline 36 & $\begin{array}{l}37.5 \\
35.6 \\
38.4\end{array}$ & $\begin{array}{l}61.4 \\
66.1 \\
58.2\end{array}$ & $\begin{array}{l}36.4 \\
30.4 \\
37.2\end{array}$ & $\begin{array}{l}2.2 \\
3.5 \\
4.6 \\
\end{array}$ & $\begin{array}{l}15.3 \\
18.6 \\
20.1\end{array}$ & $\begin{array}{l}81.5 \\
74.9 \\
73.6 \\
\end{array}$ & $\begin{array}{l}3.2 \\
6.5 \\
6.3\end{array}$ \\
\hline 48 & $\begin{array}{l}31.3 \\
30.1 \\
29.3\end{array}$ & $\begin{array}{l}69.2 \\
72.2 \\
74.4\end{array}$ & $\begin{array}{l}26.5 \\
24.3 \\
21.6\end{array}$ & $\begin{array}{l}4.3 \\
3.5 \\
4.0\end{array}$ & $\begin{array}{l}78.9 \\
83.1 \\
76.9\end{array}$ & $\begin{array}{l}15.9 \\
10.2 \\
14.8\end{array}$ & $\begin{array}{l}5.2 \\
6.7 \\
8.3\end{array}$ \\
\hline 60 & $\begin{array}{l}0.0 \\
0.0 \\
0.0\end{array}$ & & & & & & \\
\hline
\end{tabular}

Table 2. Fertilization and further development of aged eggs of Anthocidaris crassispina.

Water temperature $; 27^{\circ} \mathrm{C}$

\begin{tabular}{|c|c|c|c|c|c|c|c|}
\hline \multirow{2}{*}{$\begin{array}{l}\text { Hours to } \\
\text { insemination }\end{array}$} & \multirow{2}{*}{$\frac{\text { Fertiliz. }}{\begin{array}{c}\text { membrane } \\
\text { formation }\end{array}}$} & \multicolumn{3}{|c|}{ First cleavage $(60 \mathrm{~min})}$. & \multicolumn{3}{|c|}{ Gastrulation (12 hrs.) } \\
\hline & & 1 cell & $\begin{array}{c}2 \text { cell } \\
\text { (normal) }\end{array}$ & $\begin{array}{c}\text { multi-cell } \\
\text { (polyspermy) }\end{array}$ & $\begin{array}{c}\text { permanent } \\
\text { blastula }\end{array}$ & $\begin{array}{l}\text { gastrula } \\
\text { (normal) }\end{array}$ & exogastrula \\
\hline 0 & $\begin{array}{l}99.8 \% \\
98.8\end{array}$ & $\begin{array}{l}0.4 \% \\
0.8\end{array}$ & $\begin{array}{l}99.6 \% \\
98.8\end{array}$ & $\begin{array}{l}0.0 \% \\
0.4\end{array}$ & $\begin{array}{l}1.8 \% \\
8.5\end{array}$ & $\begin{array}{l}98.2 \% \\
91.5\end{array}$ & $\begin{array}{l}0.0 \% \\
0.0\end{array}$ \\
\hline 3 & $\begin{array}{l}95.2 \\
92.5\end{array}$ & $\begin{array}{l}10.2 \\
11.5\end{array}$ & $\begin{array}{l}89.3 \\
88.2\end{array}$ & $\begin{array}{l}0.5 \\
0.3\end{array}$ & $\begin{array}{l}2.3 \\
9.5\end{array}$ & $\begin{array}{l}97.7 \\
90.2\end{array}$ & $\begin{array}{l}0.0 \\
0.3\end{array}$ \\
\hline 6 & $\begin{array}{l}83.5 \\
81.3\end{array}$ & $\begin{array}{l}19.4 \\
14.5\end{array}$ & $\begin{array}{l}80.2 \\
77.3\end{array}$ & $\begin{array}{l}0.4 \\
8.2\end{array}$ & $\begin{array}{r}3.3 \\
11.2\end{array}$ & $\begin{array}{l}96.7 \\
88.4\end{array}$ & $\begin{array}{l}0.0 \\
0.4\end{array}$ \\
\hline 9 & $\begin{array}{l}69.2 \\
63.5\end{array}$ & $\begin{array}{l}40.3 \\
36.9\end{array}$ & $\begin{array}{l}55.2 \\
56.2\end{array}$ & $\begin{array}{l}4.5 \\
6.9\end{array}$ & $\begin{array}{r}4.3 \\
11.5\end{array}$ & $\begin{array}{l}95.6 \\
88.1\end{array}$ & $\begin{array}{l}0.1 \\
0.4\end{array}$ \\
\hline 12 & $\begin{array}{l}27.3 \\
13.2\end{array}$ & $\begin{array}{l}75.4 \\
87.8\end{array}$ & $\begin{array}{l}24.3 \\
12.1\end{array}$ & $\begin{array}{l}0.3 \\
0.1\end{array}$ & $\begin{array}{l}\text { 19. } 3 \\
43.2\end{array}$ & $\begin{array}{l}80.5 \\
56.3\end{array}$ & $\begin{array}{l}0.2 \\
0.5\end{array}$ \\
\hline 18 & $\begin{array}{l}14.3 \\
10.2\end{array}$ & $\begin{array}{l}88.6 \\
90.5\end{array}$ & $\begin{array}{r}11.2 \\
9.3\end{array}$ & $\begin{array}{l}0.2 \\
0.2\end{array}$ & & & \\
\hline 24 & cytolysis & & & & & & \\
\hline
\end{tabular}


Table 3. Effects of the sea water pollution (around Hatakejima Island) on the fertilization and further development of aged eggs of Hemicentrotus pulcherrimus.

Test water temperature; $17^{\circ} \mathrm{C}$ (warmed).

0 hr. old eggs

\begin{tabular}{|c|c|c|c|c|c|c|c|}
\hline \multirow{2}{*}{ Water samples } & \multirow{2}{*}{\begin{tabular}{|l|} 
Fertiliz. \\
$\begin{array}{l}\text { membrane } \\
\text { formation }\end{array}$
\end{tabular}} & \multicolumn{3}{|c|}{ First cleavage (90 min.) } & \multicolumn{3}{|c|}{ Gastrulation ( $24 \mathrm{hrs}$.) } \\
\hline & & 1 cell & $\begin{array}{c}2 \text { cell } \\
\text { (normal) }\end{array}$ & $\mid \begin{array}{c}\text { multi-cell } \\
\text { (polyspermy) }\end{array}$ & $\begin{array}{c}\text { permanent } \\
\text { blastula }\end{array}$ & $\begin{array}{c}\text { gastrula } \\
\text { (normal) }\end{array}$ & exogastrul \\
\hline $\begin{array}{l}\text { Running } \\
\text { sea water of } \\
\text { Laboratory }\end{array}$ & $\begin{array}{l}99.9 \% \\
98.2 \\
99.8\end{array}$ & $\begin{array}{l}0.2 \% \\
4.2 \\
0.9\end{array}$ & $\begin{array}{l}99.8 \% \\
93.7 \\
98.8\end{array}$ & \begin{tabular}{l|}
$0.0 \%$ \\
2.1 \\
0.3
\end{tabular} & $\begin{array}{l}0.2 \% \\
0.2 \\
0.1\end{array}$ & $\begin{array}{l}99.8 \% \\
99.8 \\
99.7\end{array}$ & $\begin{array}{l}0.0 \% \\
0.0 \\
0.2\end{array}$ \\
\hline $\begin{array}{l}\text { Water from open } \\
\text { sea side of Hata- } \\
\text { kejima Surface }\end{array}$ & & & & $\begin{array}{l}0.0 \\
1.8 \\
1.1\end{array}$ & $\begin{array}{l}0.1 \\
0.2 \\
0.2\end{array}$ & & $\begin{array}{l}0.1 \\
0.0 \\
0.1\end{array}$ \\
\hline $\begin{array}{l}\text { Water from land } \\
\text { side of Hatake- } \\
\text { jima Surface }\end{array}$ & $\begin{array}{l}99 . \overline{8} \\
97.9 \\
99.6\end{array}$ & $\begin{array}{l}0.7 \\
4.7 \\
3.1\end{array}$ & & $\begin{array}{l}0.2 \\
2.4 \\
1.2\end{array}$ & $\begin{array}{l}0.3 \\
0.4 \\
0.4\end{array}$ & & $\begin{array}{l}0.1 \\
0.2 \\
0.3\end{array}$ \\
\hline $\begin{array}{l}\text { Sea water from } \\
\text { Tsunashirazu } \\
\text { cove Surface }\end{array}$ & $\begin{array}{l}99.7 \\
97.2 \\
99.6\end{array}$ & $\begin{array}{l}1.0 \\
9.8 \\
5.4\end{array}$ & $\begin{array}{l}98.5 \\
85.0 \\
92.4\end{array}$ & $\begin{array}{l}0.5 \\
5.2 \\
2.2\end{array}$ & $\begin{array}{l}0.4 \\
0.5 \\
0.8\end{array}$ & $\begin{array}{l}99.4 \\
99.1 \\
99.0\end{array}$ & $\begin{array}{l}0.2 \\
0.4 \\
0.2\end{array}$ \\
\hline
\end{tabular}

6 hrs. old eggs

\begin{tabular}{|c|c|c|c|c|c|c|c|}
\hline \multirow{2}{*}{ Water samples } & \multirow{2}{*}{$\frac{\text { Fertiliz. }}{\begin{array}{c}\text { membrane } \\
\text { formation }\end{array}}$} & \multicolumn{3}{|c|}{ First cleavage $(90 \mathrm{~min})}$. & \multicolumn{3}{|c|}{ Gastrulation (24 hrs.) } \\
\hline & & 1 cell & $\begin{array}{c}2 \text { cell } \\
\text { (normal) }\end{array}$ & $\begin{array}{c}\text { multi-cell } \\
\text { (polyspermy) }\end{array}$ & $\begin{array}{c}\text { permanent } \\
\text { blastula }\end{array}$ & $\begin{array}{c}\text { gastrula } \\
\text { (normal) }\end{array}$ & exogastrula \\
\hline $\begin{array}{l}\text { Running } \\
\text { sea water of } \\
\text { Laboratory }\end{array}$ & \begin{tabular}{|l|}
$99.8 \%$ \\
98.2 \\
98.9
\end{tabular} & $\begin{array}{l}0.4 \% \\
4.6 \\
1.2\end{array}$ & $\begin{array}{l}99.4 \% \\
92.3 \\
98.3\end{array}$ & $\begin{array}{l}0.2 \% \\
3.1 \\
0.5\end{array}$ & $\begin{array}{l}0.5 \% \\
0.7 \\
0.5\end{array}$ & $\begin{array}{l}99.3 \% \\
99.1 \\
99.2\end{array}$ & $\begin{array}{l}0.2 \% \\
0.2 \\
0.3\end{array}$ \\
\hline $\begin{array}{l}\text { Water from open } \\
\text { sea side of Hata- } \\
\text { kejima Surface }\end{array}$ & \begin{tabular}{l|}
99.6 \\
98.0 \\
99.1
\end{tabular} & $\begin{array}{l}0.8 \\
3.8 \\
1.9\end{array}$ & $\begin{array}{l}99.1 \\
92.8 \\
96.4\end{array}$ & $\begin{array}{l}0.1 \\
3.4 \\
1.7\end{array}$ & $\begin{array}{l}0.4 \\
0.6 \\
0.5\end{array}$ & $\begin{array}{l}99.3 \\
99.0 \\
99.3\end{array}$ & $\begin{array}{l}0.3 \\
0.4 \\
0.2\end{array}$ \\
\hline $\begin{array}{l}\text { Water from land } \\
\text { side of Hatake- } \\
\text { jima Surface }\end{array}$ & $\begin{array}{l}99.7 \\
97.6 \\
99.1\end{array}$ & $\begin{array}{l}2.4 \\
4.9 \\
4.3\end{array}$ & $\begin{array}{l}97.3 \\
90.9 \\
92.6\end{array}$ & $\begin{array}{l}0.3 \\
4.2 \\
3.1\end{array}$ & $\begin{array}{l}0.4 \\
2.2 \\
2.1\end{array}$ & $\begin{array}{l}99.1 \\
96.5 \\
97.0\end{array}$ & $\begin{array}{l}0.5 \\
1.3 \\
0.9\end{array}$ \\
\hline $\begin{array}{l}\text { Sea water from } \\
\text { Tsunashirazu } \\
\text { cove Surface }\end{array}$ & $\begin{array}{l}98.1 \\
96.3 \\
98.3\end{array}$ & $\begin{array}{r}11.4 \\
10.4 \\
9.7\end{array}$ & $\begin{array}{l}88.2 \\
82.8 \\
81.4\end{array}$ & $\begin{array}{l}0.4 \\
6.8 \\
8.9\end{array}$ & $\begin{array}{l}0.7 \\
3.4 \\
3.1\end{array}$ & $\begin{array}{l}98.8 \\
94.1 \\
95.1\end{array}$ & $\begin{array}{l}0.5 \\
2.5 \\
1.8\end{array}$ \\
\hline
\end{tabular}

12 hrs. old eggs

\begin{tabular}{|c|c|c|c|c|c|c|c|}
\hline \multirow{2}{*}{ Water samples } & \multirow{2}{*}{ 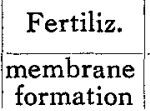 } & \multicolumn{3}{|c|}{ First cleavage (90 min.) } & \multicolumn{3}{|c|}{ Gastrulation (24 hrs.) } \\
\hline & & 1 cell & $\begin{array}{c}2 \text { cell } \\
\text { (normai) }\end{array}$ & $\begin{array}{c}\text { multi-cell } \\
\text { (polyspermy) }\end{array}$ & $\begin{array}{c}\text { permanent } \\
\text { blastula }\end{array}$ & $\begin{array}{c}\text { gastrula } \\
\text { (normal) }\end{array}$ & exogastrula \\
\hline $\begin{array}{l}\text { Running } \\
\text { sea water of } \\
\text { Laboratory }\end{array}$ & \begin{tabular}{|l|}
$80.1 \%$ \\
87.1 \\
83.6
\end{tabular} & $\begin{array}{l}20.2 \% \\
23.2 \\
31.5\end{array}$ & $\begin{array}{l}79.2 \% \\
76.5 \\
68.3 \\
\end{array}$ & $\begin{array}{l}0.6 \% \\
0.3 \\
0.2 \\
\end{array}$ & $\begin{array}{l}0.2 \% \\
0.2 \\
0.3 \\
\end{array}$ & $\begin{array}{l}99.5 \% \\
99.5 \\
99.5\end{array}$ & $\begin{array}{l}0.3 \% \\
0.3 \\
0.2\end{array}$ \\
\hline $\begin{array}{l}\text { Water from open } \\
\text { sea side of Hata- } \\
\text { kejima Surface }\end{array}$ & $\begin{array}{l}78.7 \\
89.2 \\
75.1\end{array}$ & $\begin{array}{l}22.1 \\
22.8 \\
32.1\end{array}$ & $\begin{array}{l}77.2 \\
76.7 \\
67.7\end{array}$ & $\begin{array}{l}0.7 \\
0.5 \\
0.2\end{array}$ & $\begin{array}{l}0.2 \\
0.4 \\
0.3\end{array}$ & $\begin{array}{l}99.6 \\
99.3 \\
99.6\end{array}$ & $\begin{array}{l}0.2 \\
0.3 \\
0.1\end{array}$ \\
\hline $\begin{array}{l}\text { Water from land } \\
\text { side of Hatake- } \\
\text { jima Surface }\end{array}$ & $\begin{array}{l}46.2 \\
38.4 \\
36.2\end{array}$ & $\begin{array}{l}54.0 \\
63.6 \\
64.6\end{array}$ & $\begin{array}{l}44.1 \\
35.2 \\
34.1\end{array}$ & $\begin{array}{l}1.9 \\
1.2 \\
1.3\end{array}$ & $\begin{array}{l}0.8 \\
0.6 \\
0.9\end{array}$ & $\begin{array}{l}98.8 \\
99.1 \\
98.6\end{array}$ & $\begin{array}{l}0.4 \\
0.3 \\
0.5\end{array}$ \\
\hline $\begin{array}{l}\text { Sea water from } \\
\text { Tsunashirazu } \\
\text { cove Surface }\end{array}$ & $\begin{array}{l}35.8 \\
34.3 \\
34.0\end{array}$ & $\begin{array}{l}64.6 \\
66.7 \\
66.4\end{array}$ & $\begin{array}{l}34.2 \\
32.0 \\
31.3\end{array}$ & $\begin{array}{l}1.2 \\
1.3 \\
2.3\end{array}$ & $\begin{array}{l}0.9 \\
0.7 \\
0.8\end{array}$ & $\begin{array}{l}98.5 \\
98.7 \\
98.7\end{array}$ & $\begin{array}{l}0.6 \\
0.6 \\
0.5\end{array}$ \\
\hline
\end{tabular}


Table 4. Effects of the sea water pollution (around Hatakejima Island) on the fertilization and further development of aged eggs of Anthocidaris crassispina.

Test water temperature $; 26{ }^{\circ} \mathrm{C}$.

0 hr. old eggs

\begin{tabular}{|c|c|c|c|c|c|c|c|}
\hline \multirow{2}{*}{ Water samples } & \multirow{2}{*}{$\frac{\text { Fertiliz. }}{\text { membrane }}$} & \multicolumn{3}{|c|}{ First cleavage $(60 \mathrm{~min})}$. & \multicolumn{3}{|c|}{ Gastrulation ( $15 \mathrm{hrs}$ ) } \\
\hline & & 1 cell & $\begin{array}{c}2 \text { cell } \\
\text { (normal) }\end{array}$ & $\begin{array}{c}\text { multi-cell } \\
\text { (polyspermy) }\end{array}$ & $\begin{array}{c}\text { permanent } \\
\text { blastula }\end{array}$ & $\begin{array}{l}\text { gastrula } \\
\text { (normal) }\end{array}$ & exogastrula \\
\hline $\begin{array}{l}\text { Running } \\
\text { sea water of } \\
\text { Laboratory }\end{array}$ & \begin{tabular}{|l|}
$89.3 \%$ \\
99.4 \\
84.3
\end{tabular} & $\begin{array}{c}14.8 \% \\
1.6 \\
18.5\end{array}$ & $\begin{array}{l}85.2 \% \\
98.1 \\
81.2\end{array}$ & $\begin{array}{l}0.0 \% \\
0.3 \\
0.3\end{array}$ & $\mid \begin{array}{l}0.5 \% \\
0.4 \\
0.4\end{array}$ & $\begin{array}{l}99.5 \% \\
99.5 \\
99.6\end{array}$ & $\begin{array}{l}0.096 \\
0.1 \\
0.0\end{array}$ \\
\hline $\begin{array}{l}\text { Water from open } \\
\text { sea side of Hata- } \\
\text { kejima Surface }\end{array}$ & $\begin{array}{l}93.4 \\
99.5 \\
87.2\end{array}$ & $\begin{array}{r}12.5 \\
2.1 \\
17.4\end{array}$ & $\begin{array}{l}87.2 \\
97.5 \\
82.3\end{array}$ & $\begin{array}{l}0.3 \\
0.4 \\
0.3\end{array}$ & \begin{tabular}{l|}
0.4 \\
0.4 \\
0.2
\end{tabular} & $\begin{array}{l}99.6 \\
99.5 \\
99.6\end{array}$ & $\begin{array}{l}0.0 \\
0.1 \\
0.2\end{array}$ \\
\hline $\begin{array}{l}\text { Water from land } \\
\text { side of Hatake- } \\
\text { jima Surface }\end{array}$ & $\begin{array}{l}87.3 \\
98.5 \\
81.2\end{array}$ & $\begin{array}{r}14.6 \\
4.8 \\
19.2\end{array}$ & $\begin{array}{l}84.1 \\
93.8 \\
78.4\end{array}$ & $\begin{array}{l}1.3 \\
1.4 \\
2.4\end{array}$ & $\begin{array}{l}0.3 \\
0.4 \\
0.6\end{array}$ & $\begin{array}{l}99.7 \\
99.5 \\
99.2\end{array}$ & $\begin{array}{l}0.0 \\
0.1 \\
0.2\end{array}$ \\
\hline $\begin{array}{l}\text { Sea water from } \\
\text { Tsunashirazu } \\
\text { cove Surface }\end{array}$ & $\begin{array}{l}86.5 \\
96.2 \\
77.1\end{array}$ & $\begin{array}{r}17.3 \\
9.2 \\
22.8\end{array}$ & $\begin{array}{l}81.2 \\
88.4 \\
75.1\end{array}$ & $\begin{array}{l}1.5 \\
2.4 \\
2.1\end{array}$ & $\begin{array}{l}0.5 \\
0.6 \\
0.7\end{array}$ & $\begin{array}{l}99.4 \\
99.2 \\
99.1\end{array}$ & $\begin{array}{l}0.1 \\
0.2 \\
0.2\end{array}$ \\
\hline
\end{tabular}

3 hrs. old eggs

\begin{tabular}{|c|c|c|c|c|c|c|c|}
\hline \multirow{2}{*}{ Water samples } & \multirow{2}{*}{$\mid \begin{array}{c}\text { Fertiliz. } \\
\begin{array}{c}\text { membrane } \\
\text { formation }\end{array}\end{array}$} & \multicolumn{3}{|c|}{ First cleavage $(60 \mathrm{~min})}$. & \multicolumn{3}{|c|}{ Gastrulation (15 hrs.) } \\
\hline & & 1 cell & $\begin{array}{c}2 \text { cell } \\
\text { (normal) }\end{array}$ & $\begin{array}{c}\text { multi-cell } \\
\text { (polyspermy) }\end{array}$ & $\begin{array}{c}\text { permanent } \\
\text { blastula }\end{array}$ & $\begin{array}{l}\text { gastrula } \\
\text { (normal) }\end{array}$ & exogastrula \\
\hline $\begin{array}{l}\text { Running } \\
\text { sea water of } \\
\text { Laboratory }\end{array}$ & \begin{tabular}{l|}
$83.6 \%$ \\
90.2 \\
83.5
\end{tabular} & $\begin{array}{l}23.5 \% \\
11.4 \\
26.8\end{array}$ & $\begin{array}{l}76.0 \% \\
87.2 \\
72.8\end{array}$ & $\begin{array}{l}0.5 \% \\
1.4 \\
0.4\end{array}$ & $\begin{array}{l}0.3 \% \\
0.9 \\
0.5\end{array}$ & $\begin{array}{l}99.7 \% \\
99.0 \\
99.5\end{array}$ & $\begin{array}{l}0.0 \% \\
0.1 \\
0.0\end{array}$ \\
\hline $\begin{array}{l}\text { Water from open } \\
\text { sea side of Hata- } \\
\text { kejima Surface }\end{array}$ & & & & $\begin{array}{l}0.2 \\
0.4 \\
0.3\end{array}$ & $\begin{array}{l}0.2 \\
1.2 \\
0.3\end{array}$ & $\begin{array}{l}99.8 \\
98.8 \\
99.6\end{array}$ & $\begin{array}{l}0.0 \\
0.0 \\
0.1\end{array}$ \\
\hline $\begin{array}{l}\text { Water from land } \\
\text { side of Hatake- } \\
\text { jima Surface }\end{array}$ & $\begin{array}{l}78.0 \\
84.8 \\
70.3\end{array}$ & $\begin{array}{l}31.8 \\
26.5 \\
34.7\end{array}$ & & $\begin{array}{l}4.7 \\
2.3 \\
2.1\end{array}$ & $\begin{array}{l}1.5 \\
2.3 \\
1.3\end{array}$ & $\begin{array}{l}98.3 \\
97.4 \\
98.5\end{array}$ & $\begin{array}{l}0.2 \\
0.3 \\
0.2\end{array}$ \\
\hline $\begin{array}{l}\text { Sea water from } \\
\text { Tsunashirazu } \\
\text { cove Surface }\end{array}$ & $\begin{array}{l}76.0 \\
82.1 \\
68.5\end{array}$ & $\begin{array}{l}35.0 \\
27.6 \\
42.2\end{array}$ & $\begin{array}{l}59.8 \\
69.3 \\
54.3\end{array}$ & $\begin{array}{l}5.2 \\
3.1 \\
3.5\end{array}$ & $\begin{array}{l}2.3 \\
2.5 \\
2.2\end{array}$ & $\begin{array}{l}97.5 \\
97.1 \\
97.5\end{array}$ & $\begin{array}{l}0.2 \\
0.4 \\
0.3\end{array}$ \\
\hline
\end{tabular}

6 hrs. old eggs

\begin{tabular}{l|c|c|c|c|c|c|c}
\hline \multirow{2}{*}{ Water samples } & \begin{tabular}{c} 
Fertiliz: \\
\cline { 2 - 7 }
\end{tabular} & \multicolumn{2}{|c|}{ First cleavage (60 min.) } & \multicolumn{3}{|c|}{ Gastrulation (15 hrs.) } \\
\cline { 2 - 7 } & $\begin{array}{c}\text { membrane } \\
\text { formation }\end{array}$ & 1 cell & $\begin{array}{c}2 \text { cell } \\
\text { (normal) }\end{array}$ & $\begin{array}{c}\text { multi-cell } \\
\text { (polyspermy) }\end{array}$ & $\begin{array}{c}\text { permanent } \\
\text { blastula }\end{array}$ & $\begin{array}{c}\text { gastrula } \\
\text { (normal) }\end{array}$ & exogastrula \\
Running & $75.2 \%$ & $30.4 \%$ & $68.3 \%$ & $1.3 \%$ & $13.4 \%$ & $86.5 \%$ & $0.1 \%$ \\
sea water of & 84.3 & 27.7 & 71.5 & 0.8 & 9.9 & 89.8 & 0.3 \\
Laboratory & 73.2 & 30.8 & 68.5 & 0.7 & 12.5 & 87.3 & 0.2 \\
\hline Water from open & 76.1 & 29.7 & 69.5 & 0.8 & 12.7 & 87.3 & 0.0 \\
sea side of Hata- & 83.1 & 27.0 & 72.3 & 0.7 & 9.7 & 90.2 & 0.1 \\
kejima Surface & 74.7 & 32.2 & 67.3 & 0.5 & 15.5 & 84.2 & 0.3 \\
\hline Water from land & 51.2 & 54.0 & 42.3 & 3.7 & 13.3 & 86.5 & 0.2 \\
side of Hatake- & 56.3 & 44.3 & 51.2 & 4.5 & 12.5 & 87.2 & 0.3 \\
jima Surface & 49.2 & 53.4 & 43.2 & 3.4 & 16.7 & 83.2 & 0.1 \\
Sea water from & 28.5 & 68.2 & 26.5 & 5.3 & 18.3 & 81.5 & 0.2 \\
Tsunashirazu & 30.5 & 66.8 & 28.3 & 4.9 & 16.0 & 83.5 & 0.5 \\
cove Surface & 21.3 & 75.7 & 20.1 & 4.2 & 21.2 & 78.5 & 0.3 \\
\hline
\end{tabular}


Table 5. Effects of heavy metals upon the development of aged eggs of Anthocidaris crassispina. Date : July $15-18,1973$. Water temperature: $28^{\circ} \mathrm{C}$.

\begin{tabular}{|c|c|c|c|c|c|c|c|c|c|c|}
\hline \multirow{2}{*}{\multicolumn{2}{|c|}{ Chemicals }} & \multirow{2}{*}{$\begin{array}{l}\text { Concent- } \\
\text { rations }\end{array}$} & \multirow{2}{*}{\begin{tabular}{|}
3 min. \\
after ins. \\
fertiliz. memb- \\
rane formation
\end{tabular}} & \multicolumn{3}{|c|}{$45 \mathrm{~min}$ after insemi. } & \multicolumn{3}{|c|}{12 hrs. after insemi. } & \multirow{2}{*}{$\begin{array}{l}\text { Ultimate } \\
\text { state of eggs }\end{array}$} \\
\hline & & & & $\begin{array}{l}\text { 1-cell } \\
\text { state }\end{array}$ & $\begin{array}{l}2-\text { cell } \\
\text { state }\end{array}$ & $\begin{array}{l}\text { multi-cell } \\
\text { polyspermy }\end{array}$ & $\begin{array}{c}\text { permanent } \\
\text { blastula }\end{array}$ & $\begin{array}{r}\text { normal } \\
\text { gastrula }\end{array}$ & exogastrula & \\
\hline \multicolumn{2}{|c|}{ Control water } & ppm & $99 \%$ & $2 \not 6$ & $98 \%$ & $0 \%$ & $0 \%$ & $100 \%$ & $0 \%$ & normal \\
\hline \multirow{2}{*}{$\mathrm{HgCl}_{2}$} & $\begin{array}{l}0 \mathrm{hr} . \\
\text { old eggs }\end{array}$ & $\begin{array}{l}0.5 \\
0.25 \\
0.12 \\
0.06 \\
0.03\end{array}$ & $\begin{array}{l}31 \\
66 \\
88 \\
98 \\
99\end{array}$ & $\begin{array}{r}100 \\
54 \\
17 \\
4 \\
3\end{array}$ & $\begin{array}{r}0 \\
46 \\
80 \\
96 \\
97\end{array}$ & $\begin{array}{l}0 \\
0 \\
3 \\
0 \\
0\end{array}$ & $\begin{array}{r}83 \\
19 \\
3 \\
1\end{array}$ & $\begin{array}{l}17 \\
81 \\
95 \\
99\end{array}$ & $\begin{array}{l}0 \\
0 \\
2 \\
0\end{array}$ & $\begin{array}{l}\text { cytolysis } \\
\text { retardation } \\
\text { retardation } \\
\text { almost normal } \\
\text { normal }\end{array}$ \\
\hline & $\begin{array}{l}3 \text { hrs. } \\
\text { old eggs }\end{array}$ & $\begin{array}{l}0.5 \\
0.25 \\
0.12 \\
0.06 \\
0.03\end{array}$ & $\begin{array}{l}27 \\
33 \\
63 \\
97 \\
96\end{array}$ & $\begin{array}{r}100 \\
34 \\
38 \\
8 \\
5\end{array}$ & $\begin{array}{r}0 \\
11 \\
61 \\
92 \\
95\end{array}$ & $\begin{array}{l}0 \\
5 \\
1 \\
0 \\
0\end{array}$ & $\begin{array}{r}92 \\
79 \\
32 \\
3\end{array}$ & $\begin{array}{r}8 \\
3 \\
55 \\
97\end{array}$ & $\begin{array}{r}0 \\
18 \\
13 \\
0\end{array}$ & $\begin{array}{l}\text { cytolysis } \\
\text { retardation } \\
\text { retardation } \\
\text { retardation } \\
\text { normal }\end{array}$ \\
\hline \multirow{2}{*}{$\begin{array}{l}\mathrm{CuSO}_{4} \\
5 \mathrm{H}_{2} \mathrm{O}\end{array}$} & $\begin{array}{l}0 \mathrm{hr} . \\
\text { old eggs }\end{array}$ & $\begin{array}{l}1 \\
0.5 \\
0.25 \\
0.12 \\
0.06\end{array}$ & $\begin{array}{r}3 \\
14 \\
83 \\
94 \\
98\end{array}$ & $\begin{array}{r}96 \\
57 \\
16 \\
7 \\
3\end{array}$ & $\begin{array}{r}4 \\
43 \\
82 \\
89 \\
97\end{array}$ & $\begin{array}{l}0 \\
0 \\
2 \\
4 \\
0\end{array}$ & $\begin{array}{r}25 \\
11 \\
6 \\
1\end{array}$ & $\begin{array}{l}73 \\
89 \\
94 \\
99\end{array}$ & $\begin{array}{l}2 \\
0 \\
0 \\
0\end{array}$ & $\begin{array}{l}\text { cytolysis } \\
\text { retardation } \\
\text { retardation } \\
\text { almost normal } \\
\text { normal }\end{array}$ \\
\hline & $\begin{array}{l}3 \text { hrs. } \\
\text { old eggs }\end{array}$ & $\begin{array}{l}1 \\
0.5 \\
0.25 \\
0.12 \\
0.06\end{array}$ & $\begin{array}{r}0 \\
12 \\
73 \\
90 \\
93\end{array}$ & $\begin{array}{r}100 \\
63 \\
28 \\
9 \\
6\end{array}$ & $\begin{array}{r}0 \\
37 \\
69 \\
82 \\
94\end{array}$ & $\begin{array}{l}0 \\
0 \\
3 \\
9 \\
0\end{array}$ & $\begin{array}{r}27 \\
18 \\
9 \\
3\end{array}$ & $\begin{array}{l}73 \\
79 \\
91 \\
97\end{array}$ & $\begin{array}{l}0 \\
3 \\
0 \\
0\end{array}$ & $\begin{array}{l}\text { cytolysis } \\
\text { retardation } \\
\text { retardation } \\
\text { almost normal } \\
\text { normal }\end{array}$ \\
\hline \multirow{2}{*}{$\mathrm{ZnCl}_{2}$} & $\begin{array}{l}0 \mathrm{hr} . \\
\text { old eggs }\end{array}$ & $\begin{array}{l}1 \\
0.5 \\
0.25 \\
0.12 \\
0.06\end{array}$ & $\begin{array}{r}0 \\
51 \\
93 \\
95 \\
97\end{array}$ & $\begin{array}{r}100 \\
53 \\
13 \\
9 \\
3\end{array}$ & $\begin{array}{r}0 \\
47 \\
85 \\
91 \\
97\end{array}$ & $\begin{array}{l}0 \\
0 \\
2 \\
0 \\
0\end{array}$ & $\begin{array}{l}8 \\
6 \\
3 \\
2\end{array}$ & $\begin{array}{r}6 \\
5 \\
66 \\
98\end{array}$ & $\begin{array}{r}86 \\
89 \\
31 \\
0\end{array}$ & $\begin{array}{l}\text { unfertilized } \\
\text { retardation } \\
\text { retardation } \\
\text { retardation } \\
\text { normal }\end{array}$ \\
\hline & $\begin{array}{l}3 \text { hrs. } \\
\text { old eggs }\end{array}$ & $\begin{array}{l}1 \\
0.5 \\
0.25 \\
0.12 \\
0.06\end{array}$ & $\begin{array}{r}0 \\
47 \\
89 \\
96 \\
98\end{array}$ & $\begin{array}{r}100 \\
59 \\
13 \\
8 \\
4\end{array}$ & $\begin{array}{r}0 \\
41 \\
83 \\
92 \\
96\end{array}$ & $\begin{array}{l}0 \\
0 \\
4 \\
0 \\
0\end{array}$ & $\begin{array}{l}7 \\
0 \\
2 \\
3\end{array}$ & $\begin{array}{r}4 \\
7 \\
58 \\
97\end{array}$ & $\begin{array}{r}89 \\
93 \\
40 \\
0\end{array}$ & $\begin{array}{l}\text { unfertilized } \\
\text { retardation } \\
\text { retardation } \\
\text { retardation } \\
\text { normal }\end{array}$ \\
\hline
\end{tabular}


Table 5. (continued).

\begin{tabular}{|c|c|c|c|c|c|c|c|c|c|c|}
\hline \multirow{2}{*}{$\begin{array}{l}\mathrm{CdCl}_{2} \\
2 \frac{1}{2} \mathrm{H}_{2} \mathrm{O}\end{array}$} & $\begin{array}{l}0 \mathrm{hr} . \\
\text { old eggs }\end{array}$ & $\begin{array}{c}25 \\
12 \\
6 \\
3 \\
1.5\end{array}$ & $\begin{array}{r}0 \\
43 \\
89 \\
95 \\
97\end{array}$ & $\begin{array}{r}99 \\
39 \\
16 \\
5 \\
4\end{array}$ & $\begin{array}{r}1 \\
56 \\
78 \\
95 \\
96\end{array}$ & $\begin{array}{l}0 \\
5 \\
6 \\
0 \\
0\end{array}$ & $\begin{array}{r}12 \\
4\end{array}$ & $\begin{array}{l}88 \\
96\end{array}$ & $\begin{array}{l}0 \\
0\end{array}$ & $\begin{array}{l}\text { cytolysis } \\
\text { cytolysis } \\
\text { cytolysis } \\
\text { retardation } \\
\text { norma }\end{array}$ \\
\hline & $\begin{array}{l}3 \text { hrs. } \\
\text { old eggs }\end{array}$ & $\begin{array}{c}25 \\
12 \\
6 \\
3 \\
1.5\end{array}$ & $\begin{array}{r}0 \\
13 \\
47 \\
93 \\
96\end{array}$ & $\begin{array}{r}100 \\
91 \\
69 \\
9 \\
7\end{array}$ & $\begin{array}{r}0 \\
9 \\
31 \\
91 \\
93\end{array}$ & $\begin{array}{l}0 \\
0 \\
0 \\
0 \\
0\end{array}$ & $\begin{array}{r}15 \\
5\end{array}$ & $\begin{array}{l}85 \\
95\end{array}$ & $\begin{array}{l}0 \\
0\end{array}$ & $\begin{array}{l}\text { unfertilized } \\
\text { cytolysis } \\
\text { cytolysis } \\
\text { retardation } \\
\text { normal }\end{array}$ \\
\hline \multirow{2}{*}{$\begin{array}{l}\mathrm{Pb}\left(\mathrm{CH}_{3}\right. \\
\mathrm{COO})_{2} \\
3 \mathrm{H}_{2} \mathrm{O}\end{array}$} & $\begin{array}{l}0 \mathrm{hr} . \\
\text { old eggs }\end{array}$ & $\begin{array}{r}25 \\
12 \\
6 \\
3\end{array}$ & $\begin{array}{r}0 \\
23 \\
73 \\
93\end{array}$ & $\begin{array}{r}100 \\
39 \\
24 \\
9\end{array}$ & $\begin{array}{r}0 \\
61 \\
47 \\
89\end{array}$ & $\begin{array}{r}0 \\
0 \\
29 \\
2\end{array}$ & $\begin{array}{r}15 \\
5 \\
3\end{array}$ & $\begin{array}{l}85 \\
95 \\
97\end{array}$ & $\begin{array}{l}0 \\
0 \\
0\end{array}$ & $\begin{array}{l}\text { cytolysis } \\
\text { retardation } \\
\text { retardation } \\
\text { normal }\end{array}$ \\
\hline & $\begin{array}{l}3 \text { hrs. } \\
\text { old eggs }\end{array}$ & $\begin{array}{r}25 \\
12 \\
6 \\
3\end{array}$ & $\begin{array}{r}0 \\
23 \\
81 \\
94\end{array}$ & $\begin{array}{r}100 \\
43 \\
22 \\
9\end{array}$ & $\begin{array}{r}0 \\
57 \\
57 \\
91\end{array}$ & $\begin{array}{r}0 \\
0 \\
21 \\
0\end{array}$ & $\begin{array}{r}13 \\
6 \\
4\end{array}$ & $\begin{array}{l}87 \\
94 \\
96\end{array}$ & $\begin{array}{l}0 \\
0 \\
0\end{array}$ & $\begin{array}{l}\text { cytolysis } \\
\text { retardation } \\
\text { retardation } \\
\text { normal }\end{array}$ \\
\hline \multirow{2}{*}{$\mathrm{K}_{2} \mathrm{Cr}_{2} \mathrm{O}_{7}$} & $\begin{array}{l}0 \mathrm{hr} . \\
\text { old eggs }\end{array}$ & $\begin{array}{r}100 \\
50 \\
25 \\
12 \\
6\end{array}$ & $\begin{array}{l}38 \\
78 \\
93 \\
96 \\
98\end{array}$ & $\begin{array}{r}94 \\
25 \\
12 \\
5 \\
3\end{array}$ & $\begin{array}{r}4 \\
71 \\
87 \\
95 \\
97\end{array}$ & $\begin{array}{l}2 \\
4 \\
1 \\
0 \\
0\end{array}$ & $\begin{array}{r}100 \\
7 \\
3\end{array}$ & $\begin{array}{r}0 \\
93 \\
97\end{array}$ & $\begin{array}{l}0 \\
0 \\
0\end{array}$ & $\begin{array}{l}\text { ceased } \\
\text { ceased } \\
\text { retardation } \\
\text { almost normal } \\
\text { normal }\end{array}$ \\
\hline & $\begin{array}{l}3 \text { hrs. } \\
\text { old eggs }\end{array}$ & $\begin{array}{r}100 \\
50 \\
25 \\
12 \\
6\end{array}$ & $\begin{array}{l}23 \\
83 \\
95 \\
98 \\
97\end{array}$ & $\begin{array}{r}95 \\
25 \\
8 \\
3 \\
4\end{array}$ & $\begin{array}{r}5 \\
75 \\
92 \\
97 \\
96\end{array}$ & $\begin{array}{l}0 \\
0 \\
0 \\
0 \\
0\end{array}$ & $\begin{array}{r}100 \\
9 \\
5\end{array}$ & $\begin{array}{r}0 \\
91 \\
95\end{array}$ & $\begin{array}{l}0 \\
0 \\
0\end{array}$ & $\begin{array}{l}\text { ceased } \\
\text { ceased } \\
\text { retardation } \\
\text { retardation } \\
\text { norma }\end{array}$ \\
\hline
\end{tabular}


Table 6. Effects of various chemicals other than heavy metals upon the development of aged eggs of Anthocidaris crassispina. Date: August $25-28$ 1973. Water temperature : $28^{\circ} \mathrm{C}$.

\begin{tabular}{|c|c|c|c|c|c|c|c|c|c|c|}
\hline \multirow{2}{*}{\multicolumn{2}{|c|}{ Chemicals }} & \multirow{2}{*}{$\begin{array}{l}\text { Concent- } \\
\text { rations }\end{array}$} & \multirow{2}{*}{$\mid \begin{array}{c}3 \text { min. } \\
\text { after ins. } \\
\text { fertiliz. memb- } \\
\text { rane formation }\end{array}$} & \multicolumn{3}{|c|}{$45 \mathrm{~min}$. after insem $\mathrm{i}}$. & \multicolumn{3}{|c|}{12 hrs. after insemi. } & \multirow{2}{*}{$\begin{array}{l}\text { Ultimate } \\
\text { state of eggs }\end{array}$} \\
\hline & & & & $\begin{array}{l}1 \text {-cell } \\
\text { state }\end{array}$ & $\begin{array}{l}2 \text {-cell } \\
\text { state }\end{array}$ & $\begin{array}{c}\text { multi-cell } \\
\text { polyspermy }\end{array}$ & $\begin{array}{c}\text { permanent } \\
\text { blastula }\end{array}$ & $\begin{array}{c}\text { normal } \\
\text { gastrula }\end{array}$ & exogastrula & \\
\hline \multicolumn{2}{|c|}{ Control water } & $\mathrm{ppm}$ & $98 \%$ & $3 \%$ & $97 \%$ & $0 \%$ & $1 \%$ & $99 \%$ & $0 \%$ & normal \\
\hline \multirow{2}{*}{$\mathrm{KCN}$} & $\begin{array}{l}0 \mathrm{hr} . \\
\text { old eggs }\end{array}$ & $\begin{array}{l}2.5 \\
1.2 \\
0.6 \\
0.3 \\
0.15\end{array}$ & $\begin{array}{l}38 \\
74 \\
91 \\
95 \\
97\end{array}$ & $\begin{array}{r}100 \\
100 \\
92 \\
17 \\
4\end{array}$ & $\begin{array}{r}0 \\
0 \\
8 \\
83 \\
96\end{array}$ & $\begin{array}{l}0 \\
0 \\
0 \\
0 \\
0\end{array}$ & $\begin{array}{r}19 \\
2 \\
2\end{array}$ & $\begin{array}{l}81 \\
98 \\
98\end{array}$ & $\begin{array}{l}0 \\
0 \\
0\end{array}$ & $\begin{array}{l}\text { cytolysis } \\
\text { cytolysis } \\
\text { retardation } \\
\text { almost normal } \\
\text { normal }\end{array}$ \\
\hline & $\begin{array}{l}3 \text { hrs. } \\
\text { old eggs }\end{array}$ & $\begin{array}{l}2.5 \\
1.2 \\
0.6 \\
0.3 \\
0.15\end{array}$ & $\begin{array}{l}31 \\
65 \\
82 \\
91 \\
94\end{array}$ & $\begin{array}{r}100 \\
100 \\
89 \\
11 \\
7\end{array}$ & $\begin{array}{r}0 \\
0 \\
11 \\
89 \\
93\end{array}$ & $\begin{array}{l}0 \\
0 \\
0 \\
0 \\
0\end{array}$ & $\begin{array}{r}25 \\
7 \\
5\end{array}$ & $\begin{array}{l}75 \\
93 \\
95\end{array}$ & $\begin{array}{l}0 \\
0 \\
0\end{array}$ & $\begin{array}{l}\text { cytolysis } \\
\text { cytolysis } \\
\text { retardation } \\
\text { almost normal } \\
\text { normal }\end{array}$ \\
\hline \multirow{2}{*}{ ABS } & $\begin{array}{l}0 \mathrm{hr} . \\
\text { old eggs }\end{array}$ & $\begin{array}{l}25 \\
12 \\
6 \\
3 \\
1.5\end{array}$ & $\begin{array}{r}8 \\
45 \\
91 \\
97 \\
98\end{array}$ & $\begin{array}{r}93 \\
58 \\
13 \\
9 \\
5\end{array}$ & $\begin{array}{r}7 \\
42 \\
87 \\
91 \\
95\end{array}$ & $\begin{array}{l}0 \\
0 \\
0 \\
0 \\
0\end{array}$ & $\begin{array}{r}31 \\
5 \\
4 \\
1\end{array}$ & $\begin{array}{l}69 \\
95 \\
96 \\
99\end{array}$ & $\begin{array}{l}0 \\
0 \\
0 \\
0\end{array}$ & $\begin{array}{l}\text { cytolysis } \\
\text { retardation } \\
\text { retardation } \\
\text { almost normal } \\
\text { normal }\end{array}$ \\
\hline & $\begin{array}{l}3 \text { hrs. } \\
\text { old eggs }\end{array}$ & $\begin{array}{l}25 \\
12 \\
6 \\
3 \\
1.5\end{array}$ & $\begin{array}{r}2 \\
53 \\
72 \\
96 \\
98\end{array}$ & $\begin{array}{r}98 \\
51 \\
29 \\
11 \\
4\end{array}$ & $\begin{array}{r}2 \\
49 \\
71 \\
89 \\
96\end{array}$ & $\begin{array}{l}0 \\
0 \\
0 \\
0 \\
0\end{array}$ & $\begin{array}{r}47 \\
6 \\
2\end{array}$ & $\begin{array}{l}53 \\
94 \\
98\end{array}$ & $\begin{array}{l}0 \\
0 \\
0\end{array}$ & $\begin{array}{l}\text { cytolysis } \\
\text { cytolysis } \\
\text { retardation } \\
\text { almost normal } \\
\text { normal }\end{array}$ \\
\hline \multirow{2}{*}{$\mathrm{NH}_{4} \mathrm{Cl}$} & $\begin{array}{l}0 \mathrm{hr} . \\
\text { old eggs }\end{array}$ & $\begin{array}{r}50 \\
25 \\
12 \\
6 \\
3\end{array}$ & $\begin{array}{l}86 \\
92 \\
97 \\
98 \\
98\end{array}$ & $\begin{array}{r}37 \\
10 \\
6 \\
3 \\
2\end{array}$ & $\begin{array}{l}63 \\
90 \\
94 \\
97 \\
98\end{array}$ & $\begin{array}{l}0 \\
0 \\
0 \\
0 \\
0\end{array}$ & $\begin{array}{r}100 \\
12 \\
5\end{array}$ & $\begin{array}{r}0 \\
88 \\
95\end{array}$ & $\begin{array}{l}0 \\
0 \\
0\end{array}$ & $\begin{array}{l}\text { cytolysis } \\
\text { cytolysis } \\
\text { retardation } \\
\text { retardation } \\
\text { normal }\end{array}$ \\
\hline & $\begin{array}{l}3 \text { hrs. } \\
\text { old eggs }\end{array}$ & $\begin{array}{r}50 \\
25 \\
12 \\
6 \\
3\end{array}$ & $\begin{array}{l}63 \\
83 \\
96 \\
97 \\
96\end{array}$ & $\begin{array}{r}57 \\
43 \\
16 \\
5 \\
4\end{array}$ & $\begin{array}{l}43 \\
57 \\
84 \\
95 \\
96\end{array}$ & $\begin{array}{l}0 \\
0 \\
0 \\
0 \\
0\end{array}$ & $\begin{array}{r}100 \\
21 \\
7\end{array}$ & $\begin{array}{r}0 \\
79 \\
93\end{array}$ & $\begin{array}{l}0 \\
0 \\
0\end{array}$ & $\begin{array}{l}\text { cytolysis } \\
\text { cytolysis } \\
\text { retardation } \\
\text { retardation } \\
\text { normal }\end{array}$ \\
\hline
\end{tabular}


Table 6. (continued).

\begin{tabular}{|c|c|c|c|c|c|c|c|c|c|c|}
\hline \multirow{2}{*}{$\mathrm{As}_{2} \mathrm{O}_{5}$} & $\begin{array}{l}0 \mathrm{hr} . \\
\text { old eggs }\end{array}$ & $\begin{array}{r}50 \\
25 \\
12 \\
6 \\
3\end{array}$ & $\begin{array}{r}0 \\
48 \\
89 \\
96 \\
98\end{array}$ & $\begin{array}{r}100 \\
61 \\
13 \\
7 \\
5\end{array}$ & $\begin{array}{r}0 \\
39 \\
87 \\
93 \\
95\end{array}$ & $\begin{array}{l}0 \\
0 \\
0 \\
0 \\
0\end{array}$ & $\begin{array}{r}100 \\
18 \\
9\end{array}$ & $\begin{array}{r}0 \\
82 \\
91\end{array}$ & $\begin{array}{l}0 \\
0 \\
0\end{array}$ & $\begin{array}{l}\text { unfertilized } \\
\text { cytolysis } \\
\text { retardation } \\
\text { retardation } \\
\text { normal }\end{array}$ \\
\hline & $\begin{array}{l}3 \text { hrs. } \\
\text { old eggs }\end{array}$ & $\begin{array}{r}50 \\
25 \\
12 \\
6 \\
3\end{array}$ & $\begin{array}{r}0 \\
53 \\
87 \\
93 \\
94\end{array}$ & $\begin{array}{r}100 \\
57 \\
18 \\
9 \\
4\end{array}$ & $\begin{array}{r}0 \\
43 \\
82 \\
91 \\
96\end{array}$ & $\begin{array}{l}0 \\
0 \\
0 \\
0 \\
0\end{array}$ & $\begin{array}{r}100 \\
21 \\
11\end{array}$ & $\begin{array}{r}0 \\
79 \\
89\end{array}$ & $\begin{array}{l}0 \\
0 \\
0\end{array}$ & $\begin{array}{l}\text { unfertilized } \\
\text { cytolysis } \\
\text { retardation } \\
\text { retardation } \\
\text { almost normal }\end{array}$ \\
\hline \multirow{2}{*}{$\mathrm{HCHO}$} & $\begin{array}{l}0 \mathrm{hr} . \\
\text { old eggs }\end{array}$ & $\begin{array}{r}100 \\
50 \\
25 \\
12 \\
6\end{array}$ & $\begin{array}{r}3 \\
78 \\
93 \\
98 \\
98\end{array}$ & $\begin{array}{r}100 \\
100 \\
100 \\
4 \\
2\end{array}$ & $\begin{array}{r}0 \\
0 \\
0 \\
96 \\
98\end{array}$ & $\begin{array}{l}0 \\
0 \\
0 \\
0 \\
0\end{array}$ & $\begin{array}{r}100 \\
7\end{array}$ & $\begin{array}{r}0 \\
93\end{array}$ & $\begin{array}{l}0 \\
0\end{array}$ & $\begin{array}{l}\text { cytolysis } \\
\text { cytolysis } \\
\text { cytolysis } \\
\text { retardation } \\
\text { normal }\end{array}$ \\
\hline & $\begin{array}{l}3 \text { hrs. } \\
\text { old eggs }\end{array}$ & $\begin{array}{r}100 \\
50 \\
25 \\
12 \\
6\end{array}$ & $\begin{array}{r}0 \\
71 \\
88 \\
96 \\
97\end{array}$ & $\begin{array}{r}100 \\
100 \\
100 \\
7 \\
5\end{array}$ & $\begin{array}{r}0 \\
0 \\
0 \\
93 \\
95\end{array}$ & $\begin{array}{l}0 \\
0 \\
0 \\
0 \\
0\end{array}$ & $\begin{array}{r}100 \\
11\end{array}$ & $\begin{array}{r}0 \\
89\end{array}$ & $\begin{array}{l}0 \\
0\end{array}$ & $\begin{array}{l}\text { unfertilied } \\
\text { cytoiysis } \\
\text { cytolysis } \\
\text { retardation } \\
\text { almost normal }\end{array}$ \\
\hline \multirow{2}{*}{$\mathrm{C}_{6} \mathrm{H}_{5} \mathrm{OH}$} & $\begin{array}{l}0 \mathrm{hr} . \\
\text { old eggs }\end{array}$ & $\begin{array}{r}500 \\
250 \\
120 \\
60 \\
30\end{array}$ & $\begin{array}{r}0 \\
74 \\
93 \\
97 \\
98\end{array}$ & $\begin{array}{r}100 \\
100 \\
8 \\
4 \\
3\end{array}$ & $\begin{array}{r}0 \\
0 \\
92 \\
96 \\
97\end{array}$ & $\begin{array}{l}0 \\
0 \\
0 \\
0 \\
0\end{array}$ & $\begin{array}{r}100 \\
13 \\
5\end{array}$ & $\begin{array}{r}0 \\
87 \\
95\end{array}$ & $\begin{array}{l}0 \\
0 \\
0\end{array}$ & $\begin{array}{l}\text { unfertilized } \\
\text { cytolysis } \\
\text { retardation } \\
\text { retardation } \\
\text { normal }\end{array}$ \\
\hline & $\begin{array}{l}3 \text { hrs. } \\
\text { old eggs }\end{array}$ & $\begin{array}{r}500 \\
250 \\
120 \\
60 \\
30\end{array}$ & $\begin{array}{r}0 \\
65 \\
91 \\
96 \\
97\end{array}$ & $\begin{array}{r}100 \\
100 \\
49 \\
9 \\
5\end{array}$ & $\begin{array}{r}0 \\
0 \\
51 \\
91 \\
95\end{array}$ & $\begin{array}{l}0 \\
0 \\
0 \\
0 \\
0\end{array}$ & $\begin{array}{r}100 \\
21 \\
9\end{array}$ & $\begin{array}{r}0 \\
79 \\
91\end{array}$ & $\begin{array}{l}0 \\
0 \\
0\end{array}$ & $\begin{array}{l}\text { unfertilized } \\
\text { cytolysis } \\
\text { retardation } \\
\text { retardation } \\
\text { almost normal }\end{array}$ \\
\hline
\end{tabular}


Table 7. Effects of the drainage from a plating shop upon the development of aged eggs of Anthocidaris crassispina. Date : Sept. 14,1973 . Water temperature : $25^{\circ} \mathrm{C}$.

3 hrs. old eggs

\begin{tabular}{|c|c|c|c|c|c|c|c|c|c|}
\hline \multirow{2}{*}{ Location } & \multirow{2}{*}{\begin{tabular}{|c|} 
Fertiliz. \\
membrane \\
formation
\end{tabular}} & \multicolumn{3}{|c|}{ First cleavage $(60 \mathrm{~min})}$. & \multicolumn{3}{|c|}{ Gastrulation (15 hrs.) } & \multirow{2}{*}{$\frac{\text { Other notes }}{\text { abnormal develop. }}$} & \multirow{2}{*}{$\begin{array}{l}\text { Degree of } \\
\text { inhibitory } \\
\text { effect II }\end{array}$} \\
\hline & & 1 cell & $\begin{array}{c}2 \text { cell } \\
(\text { normal })\end{array}$ & $\begin{array}{c}\text { multi-cell } \\
\text { (polyspermy) }\end{array}$ & $\begin{array}{c}\text { permanent } \\
\text { blastula }\end{array}$ & $\begin{array}{l}\text { gastrula } \\
\text { (normal) }\end{array}$ & exogastrula & & \\
\hline $\begin{array}{l}\text { Running } \\
\text { sea water of } \\
\text { Laboratory }\end{array}$ & \begin{tabular}{|l|}
$97.5 \%$ \\
98.5 \\
96.5 \\
\end{tabular} & $\begin{array}{l}3.0 \% \\
2.5 \\
4.0\end{array}$ & $\begin{array}{l}97.0 \% \\
97.5 \\
96.0\end{array}$ & $\begin{array}{l}0.0 \% \\
0.0 \\
0.0\end{array}$ & $1.0 \%$ & $99.0 \%$ & $0.0 \%$ & & 0 \\
\hline $\begin{array}{l}\text { Artificial } \\
\text { sea water } \\
\text { (Jamarin) }\end{array}$ & $\begin{array}{l}95.5 \\
96.5 \\
95.0\end{array}$ & $\begin{array}{l}5.0 \\
4.5 \\
6.0\end{array}$ & \begin{tabular}{l|}
95.0 \\
95.5 \\
94.0
\end{tabular} & $\begin{array}{l}0.0 \\
0.0 \\
0.0\end{array}$ & 2.0 & 98. 0 & 0.0 & & 0 \\
\hline $\begin{array}{l}\text { Drainage } \\
\text { from plating } \\
\text { shop }\end{array}$ & $\begin{array}{l}59.5 \\
69.0 \\
57.0\end{array}$ & $\begin{array}{l}46.5 \\
33.5 \\
45.5\end{array}$ & $\begin{array}{l}53.5 \\
66.5 \\
54.5\end{array}$ & $\begin{array}{l}0.0 \\
0.0 \\
0.0\end{array}$ & 100.0 & 0.0 & 0.0 & retardation & 5 \\
\hline $\begin{array}{l}\text { Extract from* } \\
\text { black mud of } \\
\text { the waterway }\end{array}$ & $\begin{array}{l}37.5 \\
41.0 \\
40.5\end{array}$ & $\begin{array}{l}68.5 \\
62.5 \\
66.5\end{array}$ & $\begin{array}{l}31.5 \\
37.5 \\
33.5\end{array}$ & $\begin{array}{l}0.0 \\
0.0 \\
0.0\end{array}$ & 87.5 & 12.5 & 0.0 & retardation & 5 \\
\hline $\begin{array}{l}\text { Extract from } \\
\text { sandy mud of } \\
\text { the waterway }\end{array}$ & $\begin{array}{l}73.5 \\
80.5 \\
76.5\end{array}$ & $\begin{array}{l}27.5 \\
21.5 \\
26.5\end{array}$ & $\begin{array}{l}72.5 \\
78.5 \\
73.5\end{array}$ & $\begin{array}{l}0.0 \\
0.0 \\
0.0\end{array}$ & 19.5 & 80.5 & 0.0 & $\begin{array}{l}\text { somewhat } \\
\text { retardation }\end{array}$ & 3 \\
\hline
\end{tabular}

* 9 artificial sea water was added to 1 mud or sandy mud collected from the waterway from a plating shop, shaken for 5 min. and then kept still for 6 hours., the supernatant water was used for bioassay.

Table 8. An improved ranking (the Ranking II) of the sea water pollution by using aged eggs of sea urchins.

\begin{tabular}{|c|c|c|c|c|c|c|c|c|c|}
\hline \multirow{2}{*}{ Inhibitory degree } & \multirow{2}{*}{$\begin{array}{l}\text { Stage } \\
\text { Grade }\end{array}$} & \multirow{2}{*}{\begin{tabular}{|c|} 
Fertiliz. \\
$\begin{array}{c}\text { membrane } \\
\text { formation }\end{array}$
\end{tabular}} & \multicolumn{3}{|c|}{ First cleavage } & \multicolumn{3}{|c|}{ Gastrulation } & \multirow{2}{*}{ Remarks** } \\
\hline & & & 1 cell & $\begin{array}{c}2 \text { cell } \\
\text { (normal) }\end{array}$ & $\begin{array}{c}\text { multi-cells* } \\
\text { (polyspermy) }\end{array}$ & $\begin{array}{c}\text { permanent } \\
\text { blastula }\end{array}$ & $\begin{array}{l}\text { gastrula } \\
\text { (normal) }\end{array}$ & exogastrula* & \\
\hline Violent inhibition & 5 & $0-50 \%$ & $100-50 \%$ & $0-50 \%$ & 6) $15-100 \%$ & $\mid 100-25 \%$ & $0-75 \%$ & $15-100 \%$ & $\left\{\begin{array}{l}\text { development stop- } \\
\text { ped in early stages }\end{array}\right.$ \\
\hline Strong inhibition & 4 & $51-60$ & $49-40$ & $51-60$ & $12-14$ & $24-20$ & $76-80$ & $12-14$ & $\begin{array}{l}\text { development del- } \\
\text { ayed or deformed }\end{array}$ \\
\hline Moderate inhibition & 3 & $61-70$ & $39-30$ & $61-70$ & $9-11$ & $19-15$ & $81-85$ & $9-11$ & $\begin{array}{l}\text { development some- } \\
\text { what delayed and } \\
\text { deformed }\end{array}$ \\
\hline Weak inhibition & 2 & $71-80$ & $29-20$ & $71-80$ & $6-8$ & $14-10$ & $86-90$ & $6-8$ & \\
\hline Slight inhibition & 1 & $81-90$ & $19-10$ & $81-90$ & $3-5$ & $9-5$ & $91-95$ & $3-5$ & \\
\hline Non-inhibition & 0 & $91-100$ & $9-0$ & $91-100$ & $0-2$ & $4-0$ & $96-100$ & $0-2$ & \\
\hline
\end{tabular}

*: Rather infrequent. $\quad{ }^{* *}$ : Notes when such features were seen on over $50 \%$ of the checked embryos.

Hours to insemination are 3 hours in summer (water temperature $26-28^{\circ} \mathrm{C}$ ) for Anthocidaris eggs, 9 hours in autumn (wate

temperature $13-16^{\circ} \mathrm{C}$ ) for Pseudocentrotus eggs and 6 hours in winter (water temperature $17-19^{\circ} \mathrm{C}$ warmed) for Hemicentrotus eggs 